\title{
Research
}

\section{Tibetan Sacred Sites: Understanding the Traditional Management System and Its Role in Modern Conservation}

\author{
$\underline{X i a o l i ~ S h e n ~}^{1}$, Zhi Lu ${ }^{2,3}$, Shengzhi $\mathrm{Li}^{3}$, and Nyima Chen ${ }^{3}$
}

\begin{abstract}
Sacred sites are based on indigenous culture and traditional practices that value land and lives, and are considered to be of significant contribution in biodiversity conservation. However, there is a lack of understanding about how these traditional systems function (i.e., the distribution and size of sacred sites, their management and current status), especially for those sites within the Tibetan region. From 2004 to 2007, we investigated 213 sacred mountains, a major form of Tibetan sacred site, in western China, and documented their traditional management system. We mapped 154 sacred mountains within a GIS and estimated their average size was $25.9 \mathrm{~km}^{2}$ (range $\left.0.6-208.4 \mathrm{~km}^{2}\right)$, with sacred mountains of greater religious significance covering greater areas. Monasteries had an essential role in protecting sacred mountains; $73.1 \%$ assigning specific personnel to manage their sacred mountains, and $63.9 \%$ patrolling their mountains. Official nature reserves had a remarkable spatial overlap with sacred mountains, but few reserves had established collaboration with local communities or monasteries on the land resource management. We conclude that Tibetan sacred mountains could have an important role in conservation, not only because they cover a considerable area, but also because of strong local participation in conservation of sacred mountains. We believe that Tibetan sacred sites are a landscape-level conservation attribute. To promote conservation in western China, Tibetan sacred sites need to be recognized and incorporated in the formal conservation network, and local communities should be empowered to participate in protecting and managing their sacred sites.
\end{abstract}

Key Words: informal institutions, participatory mapping, protected areas, Tibetan sacred sites, traditional land management

\section{INTRODUCTION}

Sacred sites, viewed by indigenous people with special socialspiritual context, are found in different ethnic groups throughout the world (Bhagwat and Rutte 2006, Dudley et al. 2006). They occur in various forms and at various spatial scales, such as a single plant species (Colding and Folke 2001, Kufer et al. 2006), burial grounds (Mgumia and Oba 2003, Wadley and Colfer 2004), sacred groves (Gadgil and Vartak 1974, Malhotra 2001), and even whole mountains or lakes used for religious worship (Maharana et al. 2000, Castro and Aldunate 2003, Jain et al. 2004, Xu et al. 2005). Sacred sites have been under the protection of local people for their spiritual value for generations and might be the oldest forms of protected areas in human history (Dudley et al. 2009). It has been shown that the traditional practice of sacred site worship may make significant contributions to protecting endangered species and conserving biodiversity (Decher 1997, Mgumia and Oba 2003, Bhagwat et al. 2005a, 2005b, Bossart et al. 2006), and few studies have documented the social mechanisms behind those traditional practices (Malhotra 2001, Tengö et al. 2007). Recognizing the value of sacred sites in contemporary conservation systems is advocated by numerous scholars and international nongovernmental organizations (NGOs) and has received increasing attention over the last two decades (Daniels et al. 1993, Xu et al. 2005, Bhagwat and Rutte 2006, Dudley et al. 2006, 2009).
In western China, Tibetan sacred sites have been worshiped and protected for centuries, as part of the Tibetan Buddhist practices influenced by Bon, a pre-Buddhist religion in Tibet (Feng 2005, Salick et al. 2007). Tibetan sacred sites are the abode of, or associated with, deities, nature spirits, and spiritual leaders (Jamtso 2005). They occur in several major forms, including sacred mountains, lakes, relics, forbidden areas (Ri Vgag in Tibetan), and pilgrimage routes (Ma 2005). They are based on Buddhist perspectives that value land and all living beings (Nan 2001a). Protecting the deities of mountains and lakes, and respecting all forms of life is believed to benefit the well-being of local people, their farmlands, and livestock (He 2005) and accumulate merits for individuals in pursuit of eternal happiness (Jamtso 2005).

A large number of nature reserves (the primary form of official protected areas in China) have been established in western China, and they comprise more than $75 \%$ of the area of all the reserves in China (Ministry of Environmental Protection of China (MEPC) 2008). However, management of the reserves is often ineffective due to insufficient staffing, capacity, and financial support (Liu et al. 2003, Xie 2004). Meanwhile, western China harbors rich cultural diversity; it contains more than 40 ethnic groups, comprising $89 \%$ of the total ethnic population in China (Li et al. 2008). Studies have shown that a high percentage of these ethnic groups have cultural practices that are compatible with the preservation of biodiversity $\mathrm{Xu}$ et al. 2005). A conservation policy that integrates cultural

${ }^{1}$ Center for Nature and Society, School of Life Sciences, Peking University, Beijing, 100871, China, ${ }^{2}$ Center for Nature and Society, School of Life Sciences, Peking University, Beijing, 100871, China, ${ }^{3}$ ShanShui Conservation Center, Beijing, 100871, China 
preservation has been proposed to improve the effectiveness of nature reserves (Luo et al. 2001, Xu et al. 2005, Xu and Melick 2007) but has yet to be adopted by the regional government. Thus, it is important to identify effective conservation approaches rooted in indigenous cultures and traditional practices.

The study of Tibetan sacred sites in China focused on an ethnological perspective before recently shifting to a conservation perspective (Luo et al. 2001, Nan 2001b, Ma 2005, Li et al. 2008). The significance of Tibetan sacred sites in conservation centers on their widespread distribution (Xu et al. 2005, Shen et al. 2007) and their function in conserving both mature forest (Zou et al. 2005, Salick et al. 2007, Xiang et al. 2008) and threatened species (Anderson et al. 2005). Nevertheless, our knowledge on the spatial distribution and management of Tibetan sacred sites is still poor. Previous studies are mostly conceptual discussions on the relationship between cultural practices and environmental protection $(\mathrm{Li}$ et al. 2008). Field-based studies focused on measuring biodiversity within Tibetan sacred sites (Anderson et al. 2005, Zou et al. 2005, Salick et al. 2007, Xiang et al. 2008) and not management structure.

Our paper represents the first systematic study on the spatial distribution and management institutions of Tibetan sacred sites across a large scale, as well as their potential role in conservation. We emphasized sacred mountains, one of the major forms of Tibetan sacred sites, for the large-scale mapping. The objectives were to: (1) understand the spatial pattern of Tibetan sacred sites; (2) estimate the number and land area of Tibetan sacred mountains; (3) document the management approaches on Tibetan sacred sites; and (4) compare the spatial arrangement and management system between sacred sites and nature reserves, and discuss how these two systems can be integrated to provide mutual support.

\section{METHODS}

\section{Study Area}

We conducted the study in Ganzi Tibetan Autonomous Prefecture (hereafter called "Ganzi") in Sichuan Province, China $\left(27^{\circ} 58^{\prime}-34^{\circ} 20^{\prime} \mathrm{N}\right.$ and $97^{\circ} 22^{\prime}-102^{\circ} 29^{\prime} \mathrm{E}$, Fig. 1). It consists of 18 counties, with a land area of $153,002 \mathrm{~km}^{2}$ (Committee on Ganzi Prefecture Annals (CGPA) 1997). Tibetans constitute $76 \%$ of the population in Ganzi; other ethnic groups (i.e., Han, Qiang, and Yi) mainly live along the borders of the prefecture (CGPA 1997).

Ganzi is located in the Hengduan Mountains, which are within one of the most biologically diverse temperate ecosystems in the world (Mittermeier et al. 2004). This region lies on the eastern Tibetan Plateau, with an average elevation of about $3,500 \mathrm{~m}$ (range 1,321-7,556 m) (CGPA 1997). The major vegetation types above $2,500 \mathrm{~m}$, where our study was mainly conducted, are deciduous broadleaved forest (Bethula utilis,
B. platyphylla, and Populus davidiana), evergreen broadleaved forest (Quercus sp. and Usnea longissima), deciduous conifer forest (Larix potaninii var. macrocarpa, and L. potaninii), evergreen conifer forest (Pinus, Picea, Abies, and Cupressus spp.), subalpine shrub (Rhododendron and Sabina spp.), and alpine meadow (Zhang 1997).

Fig. 1. The six sampled counties (right, gray) and 74 surveyed monasteries (right, black dots) in Ganzi Prefecture, Sichuan Province, China

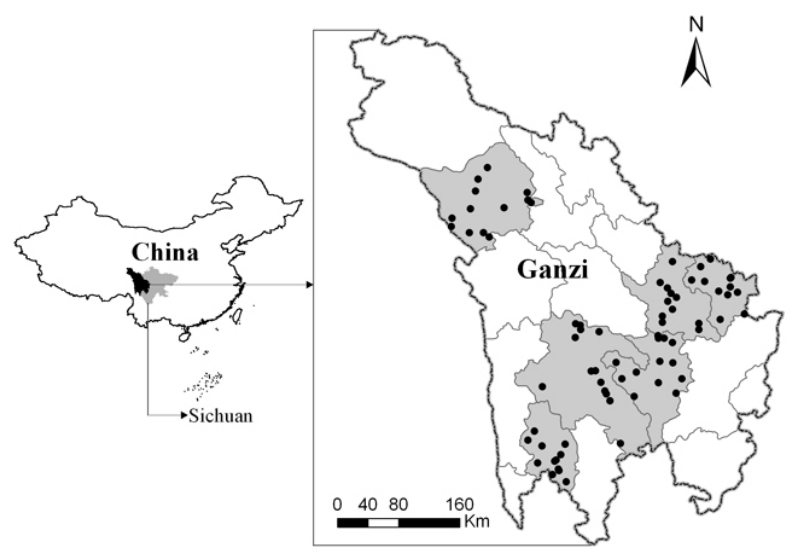

We conducted the field survey in six counties of Ganzi. The elevation of the county seats span the broad range found in the prefecture: Danba (1,850 m), Yajiang (2,580 m), Xiangcheng (2,860 m), Daofu (2,980 m), Dege $(3,270 \mathrm{~m})$, and Litang $(4,010 \mathrm{~m})$ (Fig.1). These six counties comprise $33 \%$ of the area of Ganzi.

\section{Field Survey and Data Analysis}

Almost all Tibetan sacred sites have their associated monasteries (Tsering Jigme and Tashi Dorje, personal communication). As the monasteries hold the key information about their associated sacred sites (Nan 2001b), we visited monasteries to collect information about the sacred sites. We interviewed local religious leaders, community leaders, and knowledgeable villagers at each monastery. We used a participatory mapping method (Chambers 1994) to locate the monastery, the sacred mountains and their boundaries. The information was recorded on 1:100,000 topographic maps and later verified with Global Positioning System (GPS) units. We also recorded information on the management structure of sacred mountains, the significance of each mountain, as well as its taboos, legends, and historical events. To demonstrate the spatial distribution of all forms of sacred sites and their relationship to the sacred mountains, we selected Dzongsar monastery in Dege County and mapped all the sacred sites around the monastery and its associated villages. 
We classified the sacred mountains into three hierarchical levels based on the spatial extent of their influence (Ma 2005): (1) village level-worshiped by one or several adjacent villages; (2) county level—worshiped by one county or neighboring counties; (3) Kham or Tibetan level (Kham is located in the eastern Tibetan region and is one of three districts of the entire Tibetan region based on dialect)—worshiped by the whole Kham district or by the whole Tibetan region. In addition, there were also sacred mountains worshiped by single families; but these areas were usually small and are not documented in this study. We digitized and analyzed the geospatial data within a Geographic Information System(GIS) using ArcGIS 9.2 (ESRI, California, USA). The land area of each sacred mountain was calculated using the GIS. We logtransformed the land areas for normality and used one-way analysis of variance (ANOVA) followed by Fisher's least significant difference (LSD) test to compare the land areas of sacred mountains of different hierarchical levels within SPSS 15.0 (SPSS Inc., Illinois, USA). We estimated the total number $(N)$ of sacred mountains within Ganzi as:

$$
N=M \times \frac{n}{m}
$$

where $M$ is the total number of monasteries in Ganzi $(M=515$, Dai 2007), $n$ is the number of sampled sacred mountains, and $m$ is the number of sampled monasteries;

and the total land area of sacred mountains $(S)$ as:

$$
S=N \times \sum_{i=1}^{3}\left(p_{i} \times s_{i}\right)
$$

where $i$ is the hierarchical level of sacred mountains, $p$ is the percentage of sacred mountains in each hierarchical level, and $s$ is the average land area of sacred mountains in each hierarchical level.

We collected the GIS data of reserve boundaries in our six surveyed counties from Sichuan Forestry Department. We used spatial analysis tools in ArcGIS 9.2 to examine the spatial relationship between our mapped sacred mountains and nature reserves.

\section{RESULTS}

\section{Spatial Pattern and Taboos of Tibetan Sacred Sites}

We illustrate the sacred sites of Dzongsar monastery and its associated villages as an example of how sacred sites are distributed within a traditional Tibetan community (Fig. 2a). Five forms of sacred sites were identified: sacred mountains, lakes, forbidden areas, sacred relics, and pilgrimage routes. Sacred mountains were perceived as abodes of mountain deities. They were large in size and could be identified from the prayer flags on their peaks. Their spatial extents were recognized by local monasteries and communities. Sacred lakes were perceived as abodes of riparian deities. The extents of sacred lakes were well defined by its natural edge. Forbidden areas ( $R i$ Vgag in Tibetan) were set up through agreements within local communities to prevent those areas from human disturbance, primarily for conserving the critical sacred areas. Therefore, they largely overlapped with sacred mountains and lakes. Sacred relics were associated with deities, natural spirits, and spiritual leaders and were believed to contain both sanctity and power, such as footprints of a mountain deity, caves used by famous "Rinpoches" (Tibetan lamas and other high-ranking or respected teachers), and springs occupied by deities. Sacred relics occurred in various forms (e.g., caves, stones, cliffs, springs, trees, and groves), were small in size, and could be anywhere inside or outside of sacred mountains. Pilgrimage routes were found around the monastery and sacred mountains and lakes and used for pilgrimage to worship the deities. There were three types of pilgrimage routes around the monastery: the short route close to the monastery; the medium route through important sacred sites in that area; and a long route connecting multiple monasteries and sacred sites in a larger district. Among all these forms of sacred sites, sacred mountains had the largest land cover.

Sacred mountains were important places of reference for kin identity, as an individual family would worship the same sacred mountain over generations, and a spiritual connection was believed to exist between the family and mountain deities. Each village had its own sacred mountain and sometimes several villages shared the same mountain. Monasteries were situated in the center of traditional Tibetan communities (usually including multiple adjacent villages that belonged to the same tribe prior to the modern era). Sacred mountains nearby the monasteries were respected by the whole community or a wider group of people, depending on the religious influence of the mountain (Fig. 2b). Villagers worshipped their affiliated sacred mountains every Tibetan New Year and had an annual ritual to worship the sacred mountains of the whole community during the summer.

We found a common spatial pattern of Tibetan sacred sites and their surrounding community, which could be divided into three zones (Fig. 2c): (1) Forbidden zone, areas with the most restricted rules on behavior, such as prohibitions concerning killing animals and harvesting plants. Only religious rituals and pilgrimages were permitted within this area; (2) Protected zone, other sacred areas outside the forbidden zone where hunting, logging, and farming were forbidden, but where livestock grazing (sometimes seasonal) and harvesting of nontimber forest products might be allowed. 
Fig. 2. Spatial distribution of Tibetan sacred sites (a) Sacred sites and four nature reserves around Dzongsar monastery in Ganzi Prefecture, Sichuan Province, China. (b) Spatial distribution pattern of sacred mountains around the monastery: (1) sacred mountains worshipped by single village; (2) sacred mountains shared by multiple villages; (3) sacred mountains of higher hierarchical level in the district accompanied by the monastery. ((c) The zoning pattern of a traditional Tibetan community.
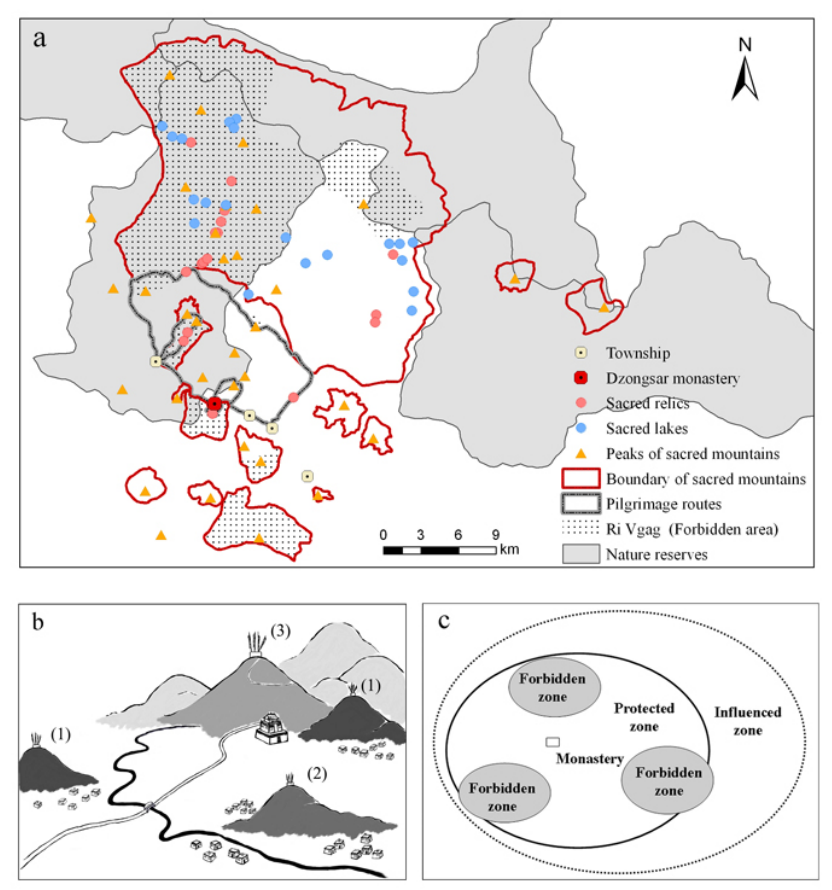

Similarly, swimming, fishing, and washing were forbidden in sacred lakes; and (3) Influenced zone, the whole community area encompassing the sacred sites. Within this area, there were no strict taboos on resource use, as long as people followed ahimsa, a baseline tenet for Buddhist conduct that includes no killing.

\section{Distribution and Management of Tibetan Sacred Mountains}

From 2004 to 2007, we visited 74 monasteries in the six counties (12-13 in each county), which accounted for 38.3\% of all monasteries in those counties. We recorded 213 sacred mountains and 154 of them were mapped within a GIS.

\section{Number and size of sacred mountains}

We recorded a mean of 2.9 sacred mountains $(\mathrm{SD}=2.6$, range $0-28$ ) around each monastery. The total land area of the sacred mountains mapped was $3990.7 \mathrm{~km}^{2}$, with an average individual size of $25.9 \mathrm{~km}^{2}\left(n=154, \mathrm{SD}=38.4 \mathrm{~km}^{2}\right.$, range 0.6-208.4 km²) (Fig. 3)
We found fewer sacred mountains at the higher hierarchical level (44 at the Kham/Tibetan level; 78at the county level; 91at the village level). Sacred mountains of the three levels differed in land area $\left(F_{2,117}=12.980, p<0.001\right)$. Sacred mountains at the county level $\left(42.2 \pm 35.5 \mathrm{~km}^{2}\right)$ or Kham/ Tibetan level $\left(53.9 \pm 66.3 \mathrm{~km}^{2}\right)$ were significantly larger in land area than those of the village level $\left(17.4 \pm 21.7 \mathrm{~km}^{2} ; \mathrm{LSD}\right.$, both $p<0.001$; Table 1). Based on our survey sample, we estimated that there were 1,480 sacred mountains in Ganzi, occupying $46,000 \mathrm{~km}^{2}$, which accounts for $30.1 \%$ of Ganzi's total land area.

Table 1. Number, average land area, and management authority of surveyed sacred mountains of different hierarchical levels in Ganzi Prefecture, Sichuan Province, China

\begin{tabular}{lcll}
\hline \hline Level & Number & $\begin{array}{l}\text { Average land } \\
\text { area }\left( \pm \mathrm{SD}, \mathrm{km}^{2}\right)\end{array}$ & Management authority \\
\hline $\begin{array}{l}\text { Village } \\
\text { County }\end{array}$ & 90 & $17.4( \pm 21.7)$ & $\begin{array}{l}\text { By village(s) } \\
\text { By associated monastery and } \\
\text { village(s) } \\
\text { By associated monastery and } \\
\text { village(s) }\end{array}$ \\
$\begin{array}{l}\text { Kham and } \\
\text { Tibetan }\end{array}$ & 44 & $53.9( \pm 66.3)$ &
\end{tabular}

\section{Management of sacred mountains}

The management of a sacred mountain was related to its hierarchical level (Table 1). Both monasteries and local villages participated in the management of sacred mountains. Monasteries played a leading role in setting up and maintaining the local regulations. To protect sacred mountains, $73.1 \%$ monasteries $(n=67)$ assigned specific guardians, who were often the disciplinarians of the monastery, to manage the sacred mountains; $63.9 \%$ monasteries $(n=72)$ organized patrolling around the mountains, but the extent and frequency of patrols varied widely. We divided the patrolling activities into two categories: irregular and regular. Irregular patrolling $(47.2 \%)$ involved activities that were not highly organized. Monks voluntarily patrolled in their spare time checking for animal snares and logging. When local villagers encountered violators or signs of them while going about their daily life, they reported to the monastery and a search was organized. Regular patrolling (16.7\%) was when specific personnel, either monks or villagers, were assigned to patrol the sacred mountains, and the number of people, frequency, and routes were fixed. Eleven monasteries with regular patrolling offered payments (material or monetary) to the patrolling staff. Another $29.2 \%$ of monasteries conducted no patrols, but reported that when people travelled around the sacred mountains during the pilgrimage, they served a patrolling function, in that they helped to uncover snares and capture poachers.

Monasteries $(n=60)$ reported that the main difficulties in the management of sacred mountains were: (1) lack of funds 
Fig. 3. Extent of the land area of Tibetan sacred mountains $(n=150)$ in the six sampled counties in Ganzi Prefecture, Sichuan Province, China.

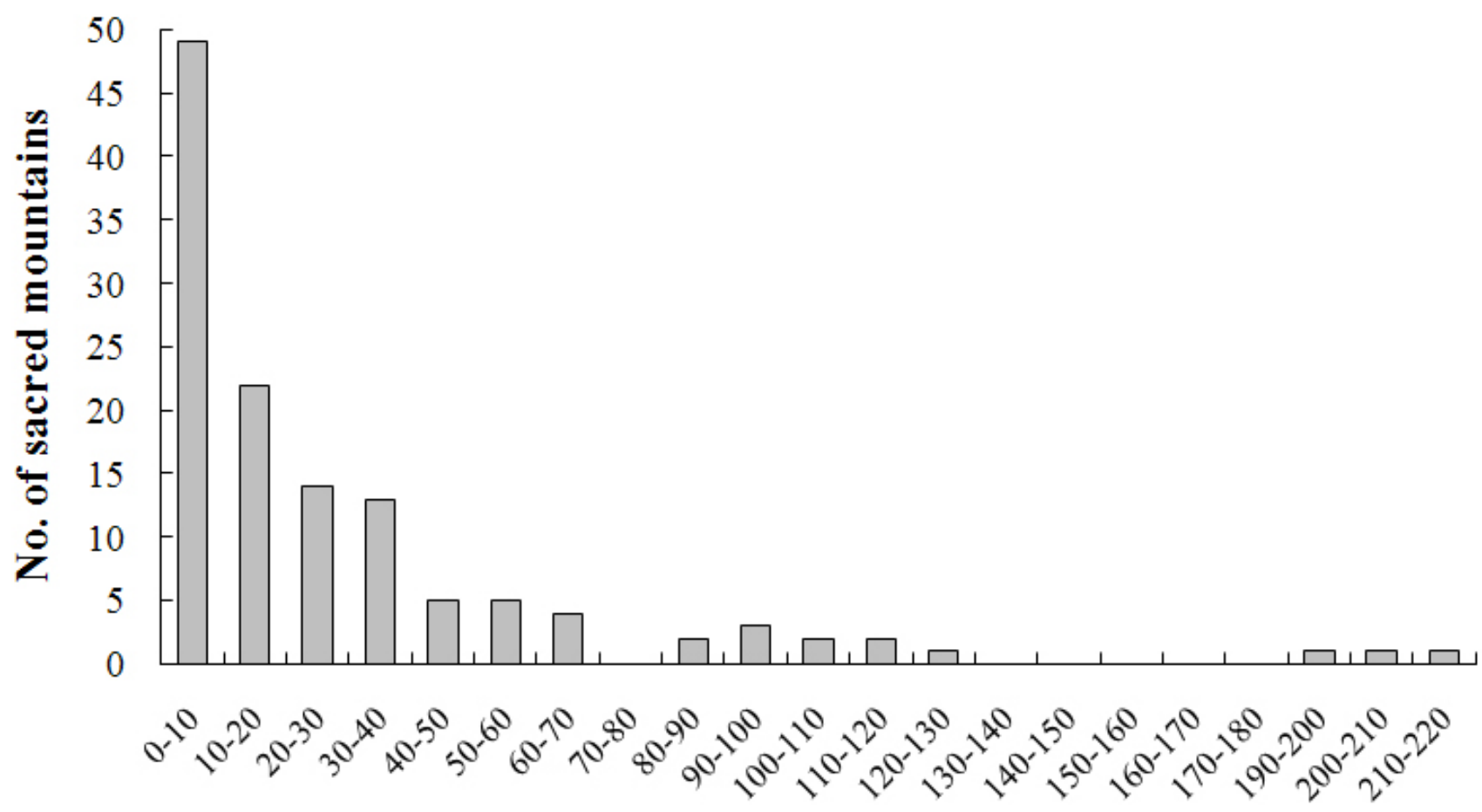

Area $\left(\mathbf{k m}^{2}\right)$

(38.3\%); (2) high pressure on the resource (30.0\%); (3) lack of legal recognition and government support (23.3\%); and (4) lack of human resources $(11.7 \%)$.

The threats to sacred mountains originated from forces that were both internal and external to the community. In general, communities that had strong traditions and organizations experienced pressures on sacred mountains from outside the community, whereas communities without strong traditions experienced more internal pressures. Forty-eight monasteries $(70 \%)$ reported that offenders were mainly outsiders, of which $26.1 \%$ were non-Tibetans, such as traders and tourists. Local communities often prevented violations, which were mainly logging and hunting, on their sacred mountains (Fig. 4). When a violation occurred and the offenders were captured by the villagers, the offenders were usually punished by oral warning, confiscation of tools, monetary fine, or sent to the monastery or local government. During our survey, three cases were recorded of people who were injured or killed during conflicts between villagers and outside offenders.

In addition to individual violations, an increase in exploitative activities by government agencies and/or commercial companies had emerged in recent years. Road construction (29.7\%), tourism $(29.7 \%)$, mining $(9.5 \%)$, and hydropower development (1.4\%) were reported by the monasteries as new threats to the sacred mountains.

\section{Relationship between Sacred Mountains and Nature Reserves}

We found a remarkable spatial overlap between sacred mountains and nature reserves. There were 17 nature reserves in the six counties we surveyed. We found each contained at least one (maximum of 13) sacred mountain. Among the 154 mapped sacred mountains, $19.3 \%$ were entirely located within the reserves $\left(615.1 \mathrm{~km}^{2}\right.$ in land area), $12.7 \%$ partially overlapped with the reserves $\left(1,585.0 \mathrm{~km}^{2}\right)$, and $68.0 \%$ were outside of any reserves $\left(1,790.6 \mathrm{~km}^{2}\right)$. As an example, we provided the spatial overlap between sacred mountains and the four nature reserves around Dzongsar monastery (Fig. 2a); sacred mountains expanded the area under conservation status and had the potential to serve as wildlife corridors between multiple reserves. 
Fig. 4. Photo on the left shows a sacred mountain (foreground) with dense primary forest and the other side of the non-sacred mountain (background) in the valley with commercially logged patches; photo on the right shows the big conifer trees on a sacred mountain in Ganzi Prefecture, Sichuan Province, China.

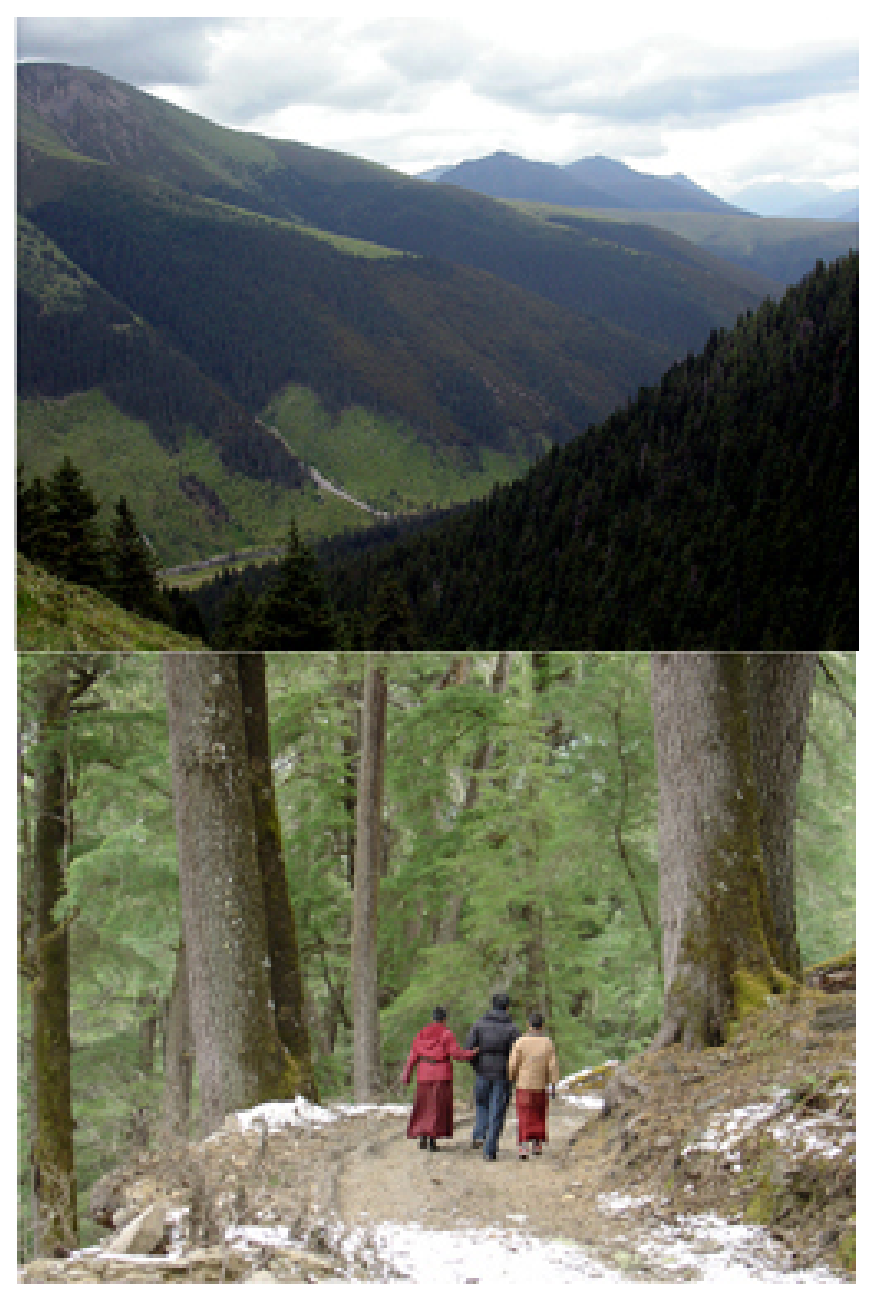

However, we recorded little collaboration on land management between reserve administrations and monasteries except for one case. The monasteries had slightly more collaboration with county forest departments, which are responsible for forest and wildlife protection (Table 2). Local forest departments provided two monasteries with funding for forest fire prevention and participated in, or financially supported, the patrolling activities organized by another five monasteries. One monastery received authorization from the local forest department to manage the sacred mountains through a written agreement in 1996. Under this agreement, they could legally stop outsiders who violated the regulations of their sacred mountains.

Table 2. Spatial relationship between monasteries $(n=74)$ and nature reserves $(n=17)$ and management categories of sacred mountains in Ganzi Prefecture, Sichuan Province, China

\begin{tabular}{lcc}
\hline Management categories & $\begin{array}{c}\text { Inside nature } \\
\text { reserves }\end{array}$ & $\begin{array}{c}\text { Outside nature } \\
\text { reserves }\end{array}$ \\
\hline $\begin{array}{l}\text { Written agreement reached between } \\
\text { communities and local government (nature } \\
\text { reserve/forest department) }\end{array}$ & 1 & 0 \\
$\begin{array}{l}\text { Managed by communities and local } \\
\text { government with an oral agreement }\end{array}$ & 1 & 6 \\
Managed by communities only & 14 & 52 \\
\hline
\end{tabular}

\section{DISCUSSION}

\section{Tibetan Sacred Sites Serve as a Landscape-level Conservation Measure}

Most of the sacred sites in the world are small. In Tanzania, the size of eight surveyed sacred groves varies from $0.1-0.3$ ha (Mgumia and Oba 2003). In southern India, the average size of sacred groves is 13.2 ha ( $n=25$, range $0.2-48.1$ ha) (Bhagwat et al. 2005b), and the average size of sacred groves throughout India is estimated at 9.6 ha $(n=4415$, total area $=$ 42,278 ha) (Malhotra 2001). These small sacred groves can be effective in protecting endangered species (Jamir and Pandey 2003, Ramanujam and Cyril 2003), but are unable to conserve the entire ecosystem. In contrast, the Tibetan sacred mountains we mapped were remarkably large and widely distributed, allowing for protection of a higher biodiversity, and ecosystem services such as the delivery of clean water. Our estimated land cover of sacred mountains in Ganzi $(30.1 \%)$ was close to the independent estimate from a local expert on Tibetan culture (30-40\%; Tsering Jigme, personal communication). Sacred mountains, together with other types of sacred sites, form a large-scale sacred landscape in the Tibetan region.

We found that the size of Tibetan sacred mountains varied widely (range $0.6-208.4 \mathrm{~km}^{2}$, mean $=25.9 \mathrm{~km}^{2}$ ). Although there was a considerable coverage of sacred mountains, a large proportion of them covered only a small area (56.8\% were < $20 \mathrm{~km}^{2}$ ). These sacred mountains were probably too small to maintain viable populations of large-bodied animals. For example, Asiatic black bears, Ursus thibetanus, typically have an individual home range of 16-202 $\mathrm{km}^{2}$ (Reid et al. 1991, Hwang 2003); some large felids (e.g., leopard Panthera pardus and snow leopard Uncia uncia) require even larger areas for hunting (Norton and Lawson 1985). Small sacred mountains are not able to wholly contain a population of such species, but they could contribute to their conservation by 
serving as "stepping stones" between larger landscapes for dispersing individuals (Tischendorf and Fahrig 2000). Sacred mountains of higher hierarchical levels were much larger in size, which therefore ensures them a higher priority in a regional conservation planning.

Tibetan sacred sites, as a form of Community Conserved Area (CCAs; Oviedo 2006, Smyth 2006), have been effectively protected by local people and function to protect threatened species, biodiversity, and ecosystem services (Anderson et al. 2005, Zou et al. 2005, Salick et al. 2007, Xiang et al. 2008). In terms of access and utilization, Tibetan sacred sites were comparable to several IUCN protected area categories (IUCN 1994): Forbidden areas and sacred lakes with strict prohibitions are analogous to Category I (Strict nature reserve and wilderness areas); sacred mountains could be allocated into Categories II (National park), V (Protected landscape), or VI (Managed resource protected area), depending on how strictly the traditional regulations are executed; and monasteries and sacred relics are consistent with the definition of Category III (Natural monument). In western China, the nature reserve system has not been established on the basis of an unbiased sampling of regional biodiversity (Liu et al. 2003). When new nature reserves were proposed by local governments (normally at the county level), there was no consideration of how much the new reserves would contribute to the conservation of regional biodiversity. Tibetan sacred sites, if incorporated into the nature reserve network, could improve the comprehensiveness and representativeness of nature reserves by covering a larger area and wider variety of ecosystems.

We estimated the total area of Tibetan sacred mountains was approximately equal to the nature reserves in Ganzi (MEPC 2008). Based on the spatial arrangement of sacred mountains and nature reserves, Tibetan sacred mountains contribute to the nature reserve network in three forms: (1) Sacred mountains inside the reserves provide increased security for long-term persistence of the species and maintenance of ecosystem services; (2) Sacred mountains that are contiguous with the reserves enhance the effective size of the reserves and improve the habitat connectivity; and (3) Sacred mountains that do not overlap with current nature reserves complement the protected area system through the practices of local communities.

Despite the great potential of Tibetan sacred sites for biodiversity conservation, they have not been considered in previous regional conservation planning ( $\mathrm{Li}$ et al. 2008). It is unknown to what extent the nature reserves represent the full variety of biodiversity, and how much of an increase in protection for biodiversity would be achieved with the recognition of Tibetan sacred mountains. We suggest that a systematic conservation planning (Margules and Pressey 2000), including both nature reserves and Tibetan sacred mountains, be conducted for the Tibetan region.

\section{Integrate Tibetan Sacred Site Practices to Enhance the Management Effectiveness of Nature Reserves}

The protection of Tibetan sacred sites largely depends on local social mechanisms, which are rooted in the traditional world view and cultural values, and enacted through local institutions (Berkes et al. 2000). It is believed that protecting the integrity of sacred mountain would please the mountain deity and benefit the well-being of associated communities. This belief is a spiritual incentive for a self-disciplined protection system. Local communities have developed regulations on how to protect sacred mountains and what punishments should be applied for violations. The severest punishment is to sever the tie between the monastery and the offender. The effectiveness of the regulations within the community usually depends on the reverence of the monastery or specific lamas, the commitment of the villagers to Buddhism, and the connections among the community members (Harris 1991).

We found that most monasteries worked to prevent violations, especially those from outside the community. Like other sacred entities worldwide, the protection of Tibetan sacred sites by local communities is carried out voluntarily and direct costs are minor (North 1990, Bhagwat and Rutte 2006). Although 11 surveyed monasteries offered payments for the patrols, the annual payments were low (up to $1500 \mathrm{RMB} /$ US $\$ 230$ per person), and about the equivalent of 1 month' salary for a reserve staff person. The extent of the patrolling activity was determined by the capacity and determination of the monastery and varied widely. We found that regular patrolling was only organized by a small percentage of the monasteries due to limited funds and human resources. The conservation effectiveness of the monasteries could be greatly enhanced if their patrolling activities were financially and technically assisted by the government or NGOs.

Better patrolling activities could lead to better conservation outcomes, but the opposite may not hold true. Patrolling activity usually was a reaction to outside threats on the sacred mountains and to its wildlife. We also found that the sacred mountains in some traditional communities were well managed in the absence of regular patrolling. Community members acted as guards against external threats during their daily life, and violations could be effectively prevented. For this reason, the management effectiveness of sacred mountains was not simply linked to the patrolling efforts of the monasteries. Increasing voluntary conservation efforts through the daily activities of the villagers may also enhance the protection of sacred mountains.

Most nature reserves in the Tibetan region are poorly managed due to insufficient staff capacity and financial support. The government has often been more concerned with the number and total area of reserves rather than their effectiveness $(\mathrm{Xu}$ and Melick 2007). For example, in Ganzi, 50 out of 51 nature reserves were established after 1995 (Ministry of Environmental Protection (MEP) 2010), but fewer than 10 
staff had been assigned to manage the 42 reserves by 2004 ( $\mathrm{Li}$ 2007). In contrast, local communities have a strong will to protect their sacred mountains, but do not have management authority due to China's state-owned land tenure system (Xu and Melick 2007). There is hardly a reserve within Ganzi that does not contain human settlements, and we believe excluding local communities from the decision-making process of the reserve will only lead to conflicts. The high overlap between the sacred mountains and nature reserves suggests comanagement between local community and nature reserves has the potential to improve reserve effectiveness by harnessing the support of local people.

$\mathrm{Xu}$ and Melick (2007) have suggested a conservation concession approach to manage state-owned lands for conservation by local communities in China. In 2006, we initiated a "conservation agreement" program in the Tibetan region, during which the nature reserves and local forestry department handed over the management right of some stateowned lands to local communities through a conservation agreement. Management plans and monitoring indicators were developed. Capacity building for local communities was provided by conservation organizations, and a minor annual award for their conservation activities was provided by local government. Initial experiences suggest the conservation concession approach is relatively cost effective and may serve as a way to adopt traditional institutions to complement the official conservation network in the Tibetan region (Shen et al. 2007). Although the initial negotiations take time and human and financial resources, once the agreement is reached, the management cost of conserving the state-owned lands can be largely downloaded to local communities (Ma and Basang Lhamo 2009). The opportunity costs are low as a result of the compatibility of local resource management practices with the maintenance of wildlife habitat and the existing voluntary conservation efforts (Ma and Basang Lhamo 2009). For those traditional Tibetan communities that have a strong commitment to conserving their lands and wildlife, the compensation mechanism needs to be carefully designed to avoid the risk of shifting the conservation activities from voluntary to benefit driven, with external payments weakening internal motivations (Wunder et al. 2008). The key for the permanence of a conservation concession in Tibetan area is the continuation of local community's conservation rights. Legal recognition of the conservation concession approach, such as by the China's Protected Areas Law, which is under development, and stable financial resources are needed to ensure its wider application and sustainability.

To facilitate the participation of local community in the management of nature reserves, we propose: (1) nature reserve managers identify and map the sacred sites within the reserves, identify the main traditional management institutions, and increase their understanding of the traditional restrictions on natural resources use and the de facto natural resources use by the local community. Sound management should be based on understanding and respecting the traditional practices and involving the local community in the decision-making process (Xu and Melick 2007); (2) Involving the traditional approaches in nature reserve management, which can lead to the adoption of conservation goals in traditional Tibetan communities (Xu et al. 2005, Bhagwat and Rutte 2006). For example, it would gain the respect of local people if the boundaries of the reserves were sanctified by rituals and marked with prayer flags or other religious symbols. Conservation education through religious rituals, and carried out by the Rinpoche, will be more palatable to local people. New sacred mountains could even be created for conservation purposes (Ma 2005).

It should be noted that the traditional management system has its limitations. The enforcement of traditional rules largely depends on the local institutions. When the monasteries are weak, the rules may be loosely enforced. Poorly managed pilgrimages can cause habitat degradation if large numbers of people come to worship (Shinde 2007). Some traditionally allowed activities on sacred mountains may be damaging, such as herb collection and grazing. Driven by increasing market demands in recent decades, especially for Matsutake mushrooms and caterpillar fungus Cordyceps sinensis as food and traditional medicine, respectively, unsustainable use of the resources and excessive human disturbance have led to biodiversity declines and habitat degradation (Salick et al. 2005, Amend et al. 2010). To promote the role of traditional practices in conservation, it is necessary to revive the cultural traditions and help local communities to develop new regulations on sustainable nature resource use to meet the changing environment.

Finally, we emphasize the importance of Tibetan sacred sites in conservation, as the land inhabited by Tibetans overlaps with multiple countries and four global biodiversity hotspots (i.e., the mountains of Southeast China, mountains of Central Asia, Eastern Himalaya, and Indo-Burma) (Myers and Mittermeier 2000, Mittermeier et al. 2004). Recognizing and involving the traditional practices of sacred site protection in future conservation planning and management will greatly promote both biodiversity conservation and community development in this region and is, therefore, of global significance.

Responses to this article can be read online at: http://www.ecologyandsociety.org/voll7/iss2/art13/ responses/

\section{Acknowledgments:}

First and foremost, we thank the Tibetan local people for sharing their traditional knowledge with us and for the 
logistical support they provided for our field work. We thank W. Liu, X. T. Ding, Z. R. Jiang, B. J. Li, Luobo Jata, and all the people who contributed to data collection. We also thank Tashi Dorje, Jangyong Pengtsuo, Tsering Jigme, and Muso for consultations on Tibetan traditional knowledge. This study was financially supported by the Blue Moon Fund and conducted through the joint efforts of Peking University, Conservation International China Program, Forest Inventory and Planning Institute of Sichuan Province, Forest Department of Ganzi Prefecture, and Green Kham. We gratefully acknowledge our colleagues in the Center for Nature and Society for their thoughtful discussions on the subject. We thank W. J. McShea, G. Schaller, and S. Lifor their help with the manuscript.

\section{LITERATURE CITED}

Amend, A., Z. Fang, C. Yi, and W. C. McClatchey. 2010. Local perceptions of Matsutake mushroom management, in NW Yunnan China. Biological Conservation 143:165-172.

Anderson, D. M., J. Salick, R. K. Moseley, and X. K. Ou. 2005. Conserving the sacred medicine mountains: a vegetation analysis of Tibetan sacred sites in Northwest Yunnan. Biodiversity and Conservation 14:3065-3091. http://dx.doi.o rg/10.1007/s10531-004-0316-9

Berkes, F., J. Colding, and C. Folke. 2000. Rediscovery of traditional ecological knowledge as adaptive management. Ecological Applications 10 (5):1251-1262. http://dx.doi.org/ 10.1890/1051-0761(2000)010[1251:ROTEKA]2.0.CO;2

Bhagwat, S. A., C. G. Kushalappa, P. H. Williams, and N. D. Brown. 2005a. Landscape approach to biodiversity conservation of sacred groves in the Western Ghats of India. Conservation Biology 19:1853-1862. http://dx.doi.org/10.1111/ j.1523-1739.2005.00248.x

Bhagwat, S. A., C. G. Kushalappa, P. H. Williams, and N. D. Brown. 2005b. The role of informal protected areas in maintaining biodiversity in the Western Ghats of India. Ecology and Society 10 (1): 8. [online] URL: http://www.eco logyandsociety.org/vol10/iss1/art8/

Bhagwat, S. A., and C. Rutte. 2006. Sacred groves: potential for biodiversity management. Frontiers in Ecology and the Environment 10:519-524. http://dx.doi.org/10.1890/1540-9295 (2006)4[519:SGPFBM]2.0.CO;2

Bossart, J. L., E. Opuni-Frimpong, S. Kuudaar, and E. Nkrumah. 2006. Richness, abundance, and complementarity of fruit-feeding butterfly species in relict sacred forests and forest reserves of Ghana. Biodiversity and Conservation 15:333-359. http://dx.doi.org/10.1007/s10531-005-2574-6
Castro, V., and C. Aldunate. 2003. Sacred mountains in the highlands of the south-central Andes. Mountain Research and Development 23:73-79. http://dx.doi.org/10.1659/0276-4741 (2003)023[0073:SMITHO]2.0.CO;2

Chambers, R. 1994. The origins and practice of participatory rural appraisal. World Development 22:953-969. http://dx.doi. org/10.1016/0305-750X(94)90141-4

Colding, J., and C. Folke. 2001. Social taboos: "Invisible" systems of local resource management and biological conservation. Ecological Applications 11:584-600.

Committee on Ganzi Prefecture Annals (CGPA). 1997. Ganzi Annals. Sichuan People's Press, Chengdu, China

Dai, G. 2007. The importance of developing the culture industry in Ganzi Prefecture. Journal of Kangding Nationality Teachers College 16:18-23

Daniels, R. J. R., S. Chandran, and M. Gadgil. 1993. A strategy for conserving the biodiversity of the Uttara-Kannada District in South-India. Environmental Conservation 20:131-138. http://dx.doi.org/10.1017/S0376892900037620

Decher, J. 1997. Conservation, small mammals, and the future of sacred groves in West Africa. Biodiversity and Conservation 6:1007-1026. http://dx.doi.org/10.1023/A:1018 $\underline{991329431}$

Dudley, N., L. Higgins-Zogib, and S. Mansourian. 2006. Beyond belief: linking faiths and protected areas for biodiversity conservation. WWF and Alliance of Religions and Conservation, Gland, Switzerland.

Dudley, N., L. Higgins-zogib, and S. Mansourian. 2009. The links between protected areas, faiths, and sacred natural sites. Conservation Biology 23:568-577. http://dx.doi.org/10.1111/ j.1523-1739.2009.01201.x

Feng, Z. 2005. The conservation perspective of Tibetan Buddhism. Pages 83-89 in J. Z. Ma and J. Chen, editors. Tibetan cultures and biodiversity conservation. Yunnan Science and Technology Press, Yunnan, China.

Gadgil, M., and V. D. Vartak. 1974. The sacred groves of Western Ghats in India. Economic Botany 30(2):152-160. http://dx.doi.org/10.1007/BF02862961

Harris, R. B. 1991. Conservation prospects for musk deer and other wildlife in Southern Qinghai, China. Mountain Research and Development 11(4):353-358. http://dx.doi.org/10.2307/3 $\underline{673718}$

He, J. H. 2005. The role of Tibetan Bon religion in conservation. Pages 68-72 in J. Z. Ma and J. Chen, editors. Tibetan cultures and biodiversity conservation. Yunnan Science and Technology Press, Yunnan, China. 
Hwang, M. H. 2003. Ecology of Asiatic black bears and people-bear interactions in Yushan National Park, Taiwan. Dissertation, University of Minnesota, Minneapolis, Minnesota, USA.

IUCN. 1994. Guidelines for protected areas management categories. IUCN, Cambridge, UK and Gland, Switzerland.

Jain, A., H. B. Singh, S. C. Rai, and E. Sharma. 2004. Folklores of sacred khecheopalri lake in the Sikkim Himalaya of India: a plea for conservation. Asian Folklore Studies 63:219-302.

Jamir, S. A., and H. N. Pandey. 2003. Vascular plant diversity in the sacred groves of Jaintia Hills in northeast India. Biodiversity and Conservation 12:1497-1510. http://dx.doi.o rg/10.1023/A:1023682228549

Jamtso, K. M. 2005. The ecological concept of Tibetan traditional cultures. Journal of Kangding Nationality Teachers College 14:12-16.

Kufer, J., N. Grube, and M. Heinrich. 2006. Cacao in Eastern Guatemala-a sacred tree with ecological significance. Environment, Development and Sustainability 8:597-608. http://dx.doi.org/10.1007/s10668-006-9046-3

Li, S. Z. 2007. Conservation concession as a payment-forecosystem-services approach. Rural Economy 8:26-28.

Li, B., F. Y. Yang, S. Sun, S. Mu, Z. Y. Zhang, X. L. Shen, and Z. Lu. 2008. Review of community conserved areas studies in Southwest China. In Community Conserved Areas: a Worldwide Review of Status and Needs after Durban 2003 and CBD COP7 2004, IUCN-Commission on Environment, Economic and Social Policy (CEESP) and World Commission on Protected Area (WCPA), Gland, Switzerland. [online] URL: http://cmsdata.iucn.org/downloads/sw china_cca study.pdf

Liu, J. G., Z. Y. Ouyang, S. L. Pimm, P. H. Raven, X. K. Wang, H. Miao, and N. Y. Han. 2003. Protecting China's biodiversity. Science 300:1240-1241. http://dx.doi.org/10.1126/science.10 $\underline{78868}$

Luo, P., S. J. Pei, and J. C. Xu. 2001. Sacred site and its implications in environmental and biodiversity conservation in Yunnan, China. Journal of Mountain Science 19:327-333.

Ma, J. Z. 2005. Natural sacred sites and conservation at Mt. Khawa Karpo. Pages 33-40 in J. Z. Ma and J. Chen, editors. Tibetan cultures and biodiversity conservation. Yunnan Science and Technology Press, Yunnan, China.

Ma, H. B., and Basang Lhamo. 2009. Conservation concession: a new conservation approach in Sanjiangyuan. Qinghai Economic Research 2:35-39.

Maharana, I., S. C. Rai, and E. Sharma. 2000. Valuing ecotourism in a sacred lake of the Sikkim Himalaya, India. Environmental Conservation 27:269-277. http://dx.doi.org/1 $\underline{0.1017 / S 0376892900000308}$
Malhotra, K. C. 2001. Cultural and ecological dimensions of sacred groves in India. Indian National Science Academy, New Delhi and Indira Gandhi Rashtriya Manav Sangrahalaya, Bhopal.

Margules, C. R., and R. L. Pressey. 2000. Systematic conservation planning. Nature 405:243-253. http://dx.doi.org $\underline{110.1038 / 35012251}$

Mgumia, F. H., and G. Oba. 2003. Potential role of sacred groves in biodiversity conservation in Tanzania. Environmental Conservation 30:259-265. http://dx.doi.org/10.1017/S037689 $\underline{2903000250}$

Ministry of Environmental Protection (MEP). 2010. Nature reserves in Sichuan Province 2009. Ministry of Environmental Protection, Beijing, China. [online] URL: http://sts.mep.gov. cn/zrbhq/zrbhq/201012/t20101220_198880.htm

Ministry of Environmental Protection of China (MEPC). 2008. 2007 Report on the state of enviorment in China. Ministry of Environmental Protection of China, Beijing, China.

Mittermeier, R. A., P. R. Gil, M. Hoffmann, J. Pilgrim, T. Brooks, C. G. Mittermeier, J. Lamoreux, and G. A. B. da Fonseca. 2004. Hotspots revisited. CEMEX, Mexico.

Myers, N., and R. A. Mittermeier. 2000. Biodiversity hotspots for conservation priorities. Nature 403:853. http://dx.doi.org/ $10.1038 / 35002501$

Nan, W. Y. 2001a. Notion and function of nature worship of ancient Tibetan nationality. Nationalities Research in Qinghai 12:23-31.

Nan, W. Y. 2001b. The taboos in Tibetan areas and the role they have played in environmental protection. North West Minorities Research 3:21-29.

North D. C. 1990. Institutions, institutional change and economic performance. Cambridge University Press, Cambridge, UK.

Norton P. M., and A. B. Lawson. 1985. Radio tracking of leopards and caracals in the Stellenbosch area, Cape Province. South African Journal of Wildlife Research 15:17-24.

Oviedo, G. 2006. Community conserved areas in South America. Pages 47-55 in A. Kothari, editor. Community conserved areas. IUCN, Gland, Switzerland.

Ramanujam, M. P., and K. P. K. Cyril. 2003. Woody species diversity of four sacred groves in the Pondicherry region of South India. Biodiversity and Conservation 12:289-299. http ://dx.doi.org/10.1023/A:1021926002101

Reid, D., M. Jiang, Q. Teng, Z. Qin, and J. Hu. 1991. Ecology of the Asiatic black bear (Ursus thibetanus) in Sichuan, China. Mammalia 55:221-238. http://dx.doi.org/10.1515/mamm.199 $\underline{1.55 .2 .221}$ 
Salick, J., A. Amend, D. Anderson, K. Hoffmeister, B. Gunn, and Z. D. Fang. 2007. Tibetan sacred sites conserve old growth trees and cover in the eastern Himalayas. Biodiversity and Conservation 16:693-706. http://dx.doi.org/10.1007/s10531$\underline{005-4381-5}$

Salick, J., Y. P. Yang, and A. Amend. 2005. Tibetan land use and change near Khawa Karpo eastern Himalayas. Economic Botany 59:312-325. http://dx.doi.org/10.1663/0013-0001(2005) 059[0312:TLUACN]2.0.CO;2

Shen, X. L., S. Z. Li, F. Tian, and Z. Lu. 2007. A new approach to conservation in western China. Pages 193-215 in Institute of Environment and Development, China Academy of Social Sciences, editor. China environment and development review Vol. 3. Social Sciences Academic Press, Beijing, China.

Shinde, K. N. 2007. Pilgrimage and the environment: challenges in a pilgrimage centre. Current Issues in Tourism 10(4):343-365. http://dx.doi.org/10.2167/cit259.0

Smyth, D. 2006. Indigenous protected areas in Australia. Pages 14-20 in A. Kothari, editor. Community conserved areas. IUCN, Gland, Switzerland.

Tengö, M., K. Johansson, F. Rakotondrasoa, J. Lundberg, J.A. Andriamaherilala, J.-A. Rakotoarisoa, and T. Elmqvist. 2007. Taboos and forest governance: informal protection of hot spot dry forest in Southern Madagascar. Ambio 36:683691. http://dx.doi.org/10.1579/0044-7447(2007)36[683:TAFGIP] 2.0.CO;2

Tischendorf, L., and L. Fahrig. 2000. On the usage and measurement of landscape connectivity. Oikos 90:7-19. http: //dx.doi.org/10.1034/j.1600-0706.2000.900102.x

Wadley, R. L., and C. J. P. Colfer. 2004. Sacred forest, hunting, and conservation in West Kalimantan, Indonesia. Human Ecology 32:313-338. http://dx.doi.org/10.1023/B:HUEC.000 $\underline{0028084.30742 . \mathrm{d} 0}$

Wunder, S., B. Campbell, P. G. H. Frost, J. A. Sayer, R. Iwan, and L. Wollenberg. 2008. When donors get cold feet: the community conservation concession in Setulang (Kalimantan, Indonesia) that never happened. Ecology and Society 13(1): 12. [online] URL: http://www.ecologyandsociety.org/vol13/ iss $1 / \operatorname{art} 12 /$

Xiang H. W., J. F. Zhang, H. M. Xu, and H. Guo. 2008. Vegetation comparison of Tibetan holy mountain and ordinary mountian in Shangrila County. Journal of West China Forestry Science 37(2):46-50

Xie, Y. 2004. Review on the management system of China's nature reserves. Pages 33-51 in Y. Xie, S. Wang, and S. Peter, editors. China's protected areas. Tsinghua University Press, Beijing, China.
Xu, J. C., E. T. Ma, D. Tashi, Y. S. Fu, Z. Lu, and D. Melick. 2005. Integrating sacred knowledge for conservation: cultures and landscapes in southwest China. Ecology and Society 10:7. [online] URL: http://www.ecologyandsociety.org/vol10/iss2/ $\underline{\operatorname{art} 71}$

Xu, J. C., and D. R. Melick. 2007. Rethinking the effectiveness of public protected areas in southwestern China. Conservation Biology 21:318-328. http://dx.doi.org/10.1111/j.1523-1739.2 $\underline{006.00636 . x}$

Zhang, R. Z. 1997. Physical geography of Hengduan Mountains. Science Press, Beijing, China.

Zou, L., Z. Q. Xie, and X. K. Ou. 2005. Significance of Tibetan sacred hills in nature conservation of ShangriLa Gorge, Yunnan. Biodiversity Science 13(1):51-57 